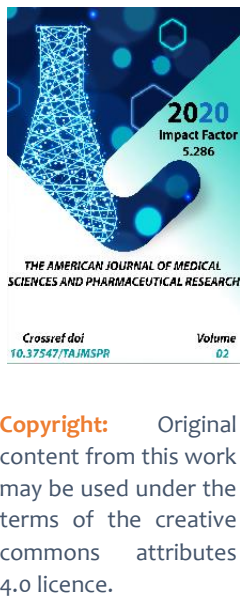

\section{Clinical And Morphological Assessment Of The Effectiveness Of Application Of Anti-Inflammatory Toothpasts In The Complex Treatment Of Periodontal Diseases In Patients With Glucose Exchange}

\author{
Xolboyeva Nasiba Asrorovna \\ Assistant, 5th Course Of The Faculty Of Dentistry Samarkand State Medical Institute, \\ Uzbekistan \\ Turayeva Kamila Furqat Qizi \\ Student 5th Course Of The Faculty Of Dentistry, Samarkand State Medical Institute, \\ Uzbekistan
}

\title{
ABSTRACT
}

One of the main causes of chronic inflammatory periodontal diseases is dental deposits, which are formed as a result of improper oral hygiene, changes in the quantitative and qualitative composition of the oral micro flora, and a decrease in the body's resistance. Compliance with individual oral hygiene is an important step in the successful treatment and prevention of periodontal disease.

\section{KEYWORDS}

Dental deposits, periodontium, individual oral hygiene, periodontal diseases.

\section{INTRODUCTION}

Currently, the number of patients with diabetes is growing every day, and this disease is getting younger. As a result, other organ systems deteriorate and, in particular, the dent alveolar system. A beautiful smile improves the appearance of a person, beautifies the face and gives self-confidence.
The purpose of our study was to identify the assessment of the effectiveness of the use of anti-inflammatory toothpastes in the complex treatment of periodontal disease in patients with diabetes mellitus and to teach the population to comply with all the rules of individual oral hygiene. 


\section{MATERIALS AND METHODS}

To conduct our study, we took 30 patients with diabetes mellitus, among them 21 men and 9 women aged 30 to 55 years, who are under observation at the Samarkand endocrinological dispensary. We divided the patients into 2 groups of 15 people each. Each patient underwent oral hygiene. We assessed the state of the oral mucosa using the following indices: SilnessLoe hygiene index, CPTIN (Community periodontal Index of Treatment), PMA periodontal index, gum bleeding index. We performed professional hygienic teeth cleaning for patients of both groups, which consisted of the following stages:

- Supra and sub gingival plaque was identified and evaluated;

- Removed non-mineralized supra- and sub gingival deposits;

- Removed mineralized supra- and sub gingival deposits;

- Eliminated roughness on the surface of the teeth, contributing to the formation of plaque;

- Polished and smoothed the surfaces of the teeth.

Complex treatment of gingivitis consisted of antiseptic treatment of the oral cavity with solutions of eludril or francolin $0.02 \%$ in the form of applications, baths and rinses. Also prescribed anti-inflammatory drugs like decoctions of calendula, chamomile and sage for rinsing at home. One patient was prescribed physiotherapy procedures to improve microcirculation in the gums, which is very important for patients with diabetes mellitus.
In the complex treatment of periodontitis, we treated the oral cavity with antiseptic solutions before and after removing dental plaque. Prescribed a course of physiotherapy for 5 days, electrophoresis and anodgalvanization.

In the presence of periodontal pockets, they were eliminated.

Complex treatment for periodontal disease was carried out in the form of gum massage, validation of the gums, local hypo- and hyperthermia, ultrasound therapy, we also used biogenic stimulants, nicotinic acid, oral cavity membranes, and we taught both groups the rules of individual oral hygiene. However, we recommended the first group: to use the Splat professional toothbrush and the Splat professional Lavendersept treatment and prophylactic toothpaste; use mouthwash and floss. They also distributed reminder plaques about brushing their teeth, where it was necessary to put a tick after each brushing.

\section{RESULTS}

During the initial examination and hygienic indices in 30 patients with diabetes mellitus, $14 \%$ had catarrhal gingivitis, $23 \%$ had generalized periodontitis of moderate severity, $63 \%$ had generalized periodontitis of moderate severity. When determining the bleeding of the gums, using a periodontal probe, we carried it lightly along the gum from the base of the papilla to the apex, along the distal and mesial surfaces of the tooth. After probing the entire square, the degree of bleeding was recorded: in 10 patients, 1 degree of bleeding was observed, i.e. single point bleeding. In 5 patients, grade 2 was observed, at which there was light linear bleeding along the edge of the papilla. In 2 patients, grade 3 bleeding was observed when moderate filling of the 
interdental triangle with blood occurred. According to the patients' complaints, we found out that with daily brushing of their teeth, bleeding was not observed, and in cases where they did not brush their teeth for at least one day, bleeding was observed (after the formation of a soft plaque).

When teaching the rules of individual oral hygiene, we gave special recommendations: teeth should be brushed 2 times a day in the morning after breakfast and in the evening before bedtime. When brushing your teeth, you should simultaneously massage the gums with a brush. You need to brush your teeth with sweeping and rotating movements for 3-5 minutes.

A month later, we re-examined the oral cavity of both groups and found that the complaints of the second group prevailed over the first. In the first group of patients, bleeding gums decreased by up to $30 \%$. The performance of the indices has improved. In patients of the second group, complaints remained as before: bleeding gums decreased to $50 \%$, the color of the gums was light red and there was a feeling of discomfort in the mouth. When interviewing patients in this group, it turned out that they did not always follow the rules of individual oral hygiene. The therapeutic and prophylactic toothpaste Splat professional Lavendersept has the following properties: desensitize effect-58\%, hemostatic effect-75\%, antiinflammatory effect- $80 \%$, and antioxidant effect-92\%.

\section{CONCLUSIONS}

The results of our study have shown the high efficiency of using the therapeutic and prophylactic toothpaste Splat professional Lavandasept and the fulfillment of all the rules of oral hygiene after the complex treatment of periodontal diseases in patients with diabetes mellitus. The effectiveness of oral hygiene depends on the regularity, thoroughness, method of use, consistency, effort and time spent. And the combined use of Splat professional Lavendersept toothpaste with lavender, rosemary and thyme essential oils protects against pathogenic bacteria and has a strong anti-inflammatory effect. The synergy of active plant oils with $\mathrm{Zn}$ salts gives a strong antioxidant effect. The use of oral rinses reduces bacterial contamination and improves oral hygiene. According to the literature, we know that patients with diabetes mellitus have a high concentration of glucose in the gingival fluid, leading to the rapid proliferation of bacteria and the formation of dental plaque. And the methods we have studied will help patients with impaired glucose metabolism to have beautiful teeth and strong gums.

\section{REFERENCES}

1. Abolmasov, N. N. Strategy and tactics of prevention of periodontal diseases / N. N. Abol-Masov / / Stomatology. - 2003. - No. 4. - P. 34 .

2. barer, G. M. periodontal Diseases. Clinic, diagnosis and treatment: textbook. manual / G. M. barer, T. I. Lemetskaya. - M.: VUNMTS, 1996. - 86 p.

3. Borovsky, E. V. Biology of the oral cavity/E. V. Borovsky, V. K. Leontiev. - Moscow: Meditsina, 1991. $-346 \mathrm{p}$.

4. Rizaev J.A. (2008). Rasprostranenost bolezney parodonta sredy gorodskogo naseleniya Uzbekistana [Prevalence of periodontal diseases among urban population of Uzbekistan] Med.jurnal Uzbekistana, (4), 55-58.

5. Sivovol S.I. (2006). Pervichnye faktori $v$ etiologii i patogeneze vospalpitelnyx zabo- 
The American Journal of Medical Sciences and Pharmaceutical Research

(ISSN - 2689-1026)

Published: December 31, 2020 | Pages: 74-77

Doi: https://doi.org/10.37547/TAJMSPR/Volume02Issue12-12

IMPACT FACTOR

2020: 5.286

OCLC - 1121105510

levaniy parodontta [Primary Factors in the

Etiology and Pathogenesis of Periodontal

Inflammatory Diseases] Stomatologiya,

(6), 37-48

6. A. I. Nikolaev, L. M. Tsepov. Practical therapeutic dentistry. --- 2017-No. 9. From

846-847 